\title{
Using Google Earth Engine to monitor co-seismic landslide recovery after the 2008 Wenchuan earthquake
}

\author{
Wentao Yang ${ }^{1}$, Wenwen $\mathrm{Qi}^{2}$, Jian Fang ${ }^{3}$ \\ ${ }^{1}$ Three-gorges reservoir area (Chongqing) Forest Ecosystem Research Station, School of Soil and Water Conservation, Beijing \\ 5 Forestry University, Beijing, 100083, China. \\ ${ }^{2}$ National Institute of Natural Hazards, Ministry of Emergency Management of China, Beijing, China \\ ${ }^{3}$ School of Urban and Environmental Sciences, Central China Normal University, Wuhan, China.
}

Correspondence to: Wentao Yang (yang_wentao@bjfu.edu.cn)

Abstract. Earthquake-triggered landslides can pose serious threats to mountain communities by remobilizing and providing

10 loose materials for debris flows in post-seismic years. However, how long co-seismic landslides recover remains elusive due to limited observations. Using vegetation dynamics, we studied surface recovery of co-seismic landslides induced by the 2008 Wenchuan earthquake from May 2008 to July 2019 for over 20,000 km². Landsat derived vegetation recovery on all co-seismic landslides has been assessed based on the Google Earth Engine, a cloud-based computing platform. We found most co-seismic landslides have been recovering after the earthquake but the spatial pattern is heterogeneous. The epicentre region with low

15 elevations along the bottom of the Min River valley has the best landslide recovery, whereas many landslides on the high Longmen Mountain are poorly recovered ten years after the earthquake. These unrecovered hillslopes and gullies together with widespread loose debris indicate that surface processes on high mountains may still active and may provide source materials for debris flows, threatening communities at low elevations. To decipher possible mechanisms, we further analysed the relations between landslide recovery and twelve influencing factors, including slope, pre-seismic vegetation condition,

20 landslide depth, landslide area, elevation, ground peak acceleration of the earthquake, aspect, slope curvatures, topographic positions, mean annual precipitation, ground cohesion strength and vegetation types. We found elevation, topographic position and pre-seismic vegetation condition are the most important factors that influence landslide recovery over all others. This work also demonstrates the efficiency of the Google Earth Engine for continuously monitoring landslide dynamics over large areas.

\section{Introduction}

25 Large earthquakes trigger thousands of hundreds of co-seismic landslides (Xu et al., 2014), denude vast area of vegetation (Cui et al., 2012), leave widespread unstable hillslopes, and have long-term impacts on landscape evolutions (Keefer, 1994; Parker et al., 2011, Yang and Qi, 2017). After major earthquakes, co-seismic landslides are widely distributed (Xu et al., 2014) and erosion from landslide surface can be massive (Sidle et al., 2011). Vegetation recovery on landslides plays a positive role on post-seismic slope stability and can be used to indicate regional slope stability after major earthquakes (Chen et al., 2020; 30 Li et al., 2016; Yang et al., 2018a). How long will the scars of a major earthquake persist not only influence post-seismic 
socioeconomic recovery (Huang and Fan, 2013) but also effects post-seismic regional erosion and orogenic mass balance (Marc et al., 2016; Parker et al., 2011).

Earthquake-triggered landslides commonly spread large spatial areas and investigations of landslides surface recovery at regional scale have been carried out by jointly using optical remote sensing images and field reconnaissance (Keefer, 2002;

35 Xu et al., 2014). Vegetation changes in remote sensing images are major features for landslide monitoring (Khan et al., 2013; Li et al., 2016; Lin et al., 2008; Mondini et al., 2011; Saba et al., 2010; Stumpf and Kerle, 2011). The 2008 Wenchuan earthquake triggered $\sim 190,000$ co-seismic landslides (Xu et al., 2014). After the earthquake, changes of landslide surfaces have been intensively studied at a few local areas. For example, in the epicentre area, the total area of landslides has been found decreasing linearly in the first five to eight years (Fan et al., 2018; Tang et al., 2016; Yang et al., 2017; Zhang et al.,

40 2014; Chen, 2020). The situation is similar in the lower Mianyuanhe watershed (Li et al., 2016) and the Hongxi watershed (Yang et al., 2015). These works on post-seismic landslide surface recovery have been carried out in very limited spatial area and observations in other parts of the earthquake-affected region is still missing, because high spatial resolution images used in these works are very expensive, and frequently influenced by bad weathers. Lack of observations on landslide changes over the entire region hinders a holistic understanding of its evolving patterns and driving factors.

45 To overcome incomplete observations of post-seismic landslides after the Wenchuan earthquake, MODIS data with large footprints and short revisit time has been used (Yang and Qi, 2017; Yunus et al., 2020). The $250 \mathrm{~m}$ resolution MODIS data is sensitive to changes of landslide surfaces after the Wenchuan earthquake (Liu et al., 2015; Zhang et al., 2018). Long-term monitoring of post-seismic landslide surface using the MODIS time series revealed a spatially heterogeneous pattern (Yang and Qi, 2017). The recovery of MODIS derived landslide surface is found sensitive to precipitation and topography (Yang et

50 al., 2018b). Despite MODIS observation can monitor the entire earthquake-affected region, its spatial resolution is much too coarse and most signals of the $250 \mathrm{~m}$ MODIS are a mixture of landslides and other ground features.

Landsat imagery is a valuable data for monitoring long-term earth surface processes at a spatial resolution of $30 \mathrm{~m}$ for multispectral bands. The finer spatial resolution of Landsat over MODIS makes it possible to map a single medium sized landslide (e.g. $30 \mathrm{~m} \times 30 \mathrm{~m}$ ) and it has been frequently used to map regional landslides (Behling et al., 2016; Chen et al., 2019; Coe et al.,

55 2018; Marc et al., 2015). Landsat 5 TM, Landsat 7 ETM and Landsat 8 OLI all have 16-day revisit interval and joint use of them lead to more frequent observations and easy comparisons for monitoring landslide surface dynamics. The short revisit time in time series of all Landsat images have the potential to overcome partial coverage problems encountered by very high spatial resolution images. Despite Landsat images also face the problem posed by clouds, some algorithms have been developed to minimize the influence of clouds (Zhu and Helmer, 2018; Zhu and Woodcock, 2012). To obtain cloud-free

60 observations, many Landsat images of different dates is needed and handling these large amounts of Landsat images could pose another challenge.

In this work, we explore a cloud-based platform, the Google Earth Engine (GEE), to map surface recovery of co-seismic landslides triggered by the $\mathrm{M}_{\mathrm{W}} 7.9$ Wenchuan earthquake in an area of 23,000 $\mathrm{km}^{2}$. This cloud-based platform has the advantage of easy-to-use and can efficiently process large volumes of data by researchers that are not familiar with remote 

recovery pattern by using large volumes of Landsat images, and 2) to explore possible factors that influence landslide recovery.

\section{Methodology}

\subsection{Study area}

The $M_{\mathrm{W}}$ 7.9 Wenchuan earthquake occurred on May 12, 2008, in the Longmen Mountain, bordering the Tibetan Plateau (average elevation $>4000 \mathrm{~m}$ ) and the Sichuan Basin $(<800 \mathrm{~m}$ ) (Fig. 1). This earthquake triggered nearly 200,000 landslides over $110,000 \mathrm{~km}^{2}$ and the total landslide area is $1,160 \mathrm{~km}^{2}$ (Xu et al., 2014). The size of these landslides varies over several orders of magnitudes, with the smallest a few square meters and the largest landslide up to $\sim 8 \mathrm{~km}^{2}$ (Hu et al., 2019). Distributed along the $>200 \mathrm{~km}$ Yingxiu-Beichuan Fault ranging from the epicentre Yingxiu town north-eastward to Qingchuang county, these landslides formed a densely distributed landslide zone (>10\% surface area disturbed by landslides) and the width of the southern section ( 25-30 km) is much larger than the northern part ( 3-5 km) (Ouimet, 2010).

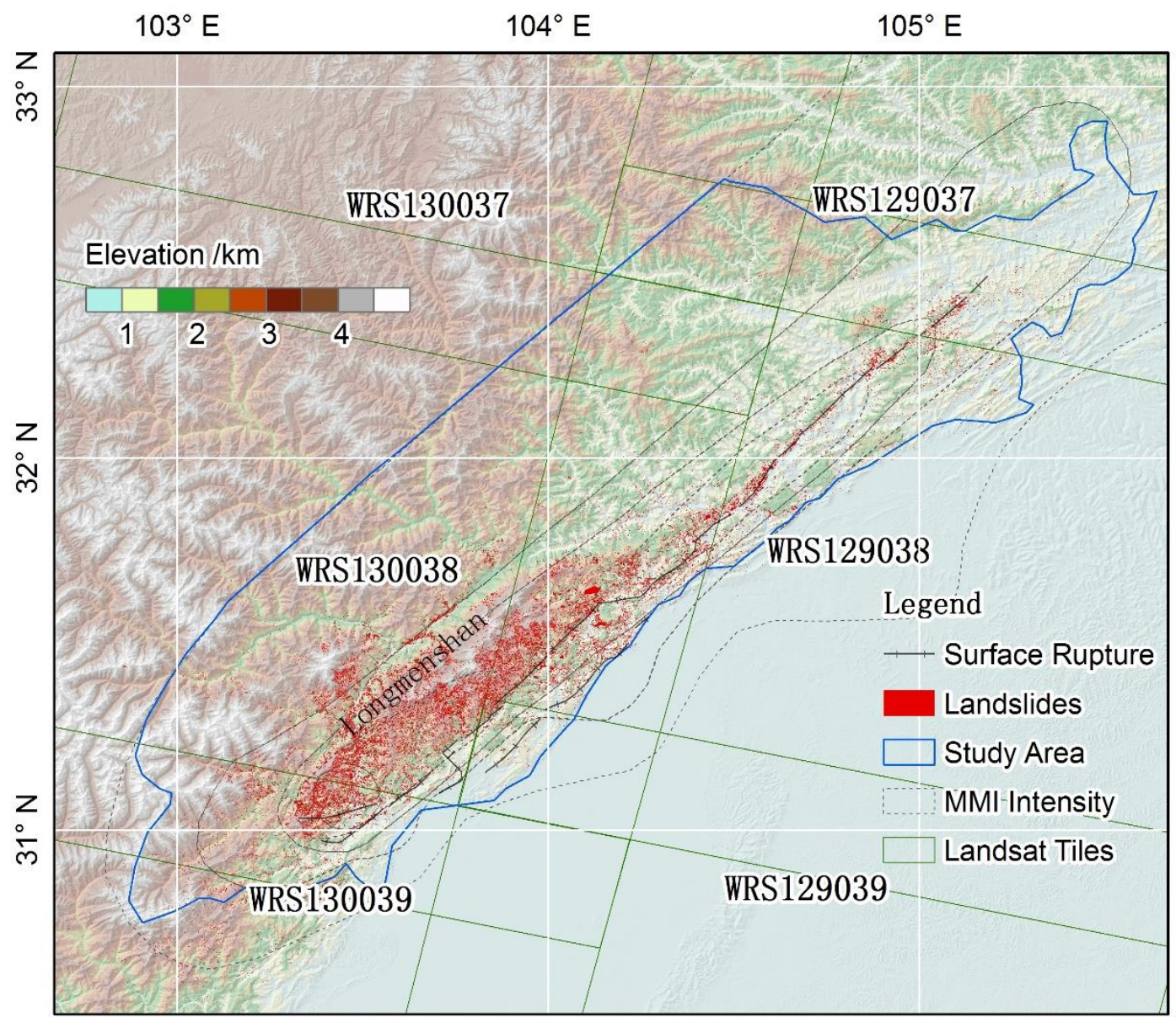


Figure 1: Study area and Landsat tiles used in this work. Landslides triggered by the 2008 earthquake are interpreted by Xu et al. (2014). The shown DEM is SRTM DEM downloaded from the USGS website. The surface rupture is digitized from the map in Xu et al. (2009). The MMI intensity lines are produced by the China Earthquake Administration and were digitized by the authors.

\subsection{Method}

This study area covers six Landsat Tiles: WRS129037, WRS129038, 129039, WRS130037, WRS130038, WRS130039 (Fig. 1). WRS129038 and WRS130038 are two major tiles that cover most part of this study area. In this work, we used Tier 1 calibrated top of atmosphere (TOA) reflectance product of the USGS Collection 1. At this level, the data is created using the best processing level (Chander et al., 2009). All Landsat 5, 7 images from 2001 to 12 May 2008 and all Landsat 5, 7, 8 images from May 2008 to July 2019 are used to study pre- and post-seismic vegetation dynamics on earthquake-triggered landslides, respectively. There are 1,167 pre-seismic images and 1,857 post-seismic Landsat images used in this work. All image processing was performed in Google Earth Engine (Gorelick et al., 2017).

Previous works show that landslides can dramatically decrease vegetation index and the recovery of vegetation index to preseismic level can be used to indicate the time of landslide surface recovery (Yang et al., 2018a; Zhang et al., 2018). In this

work, we used enhanced vegetation index (EVI) to measure vegetation recover on co-seismic landslides, because EVI is more consistent than other vegetation indexes (such as NDVI) among three types of Landsat images (Bell et al., 2018; Zhu et al., 2016).

$\mathrm{EVI}=\frac{2.5 *\left(\rho_{\text {nir }}-\rho_{\text {red }}\right)}{\rho_{\text {nir }}+6 * \rho_{\text {red }}-7.5 * \rho_{\text {blue }}+1}(1)$

where $\rho_{\text {nir }}, \rho_{\text {red, }}, \rho_{\text {blue }}$ are near infrared $(760-900 \mathrm{~nm})$, red $(630-690 \mathrm{~nm})$ and blue $(450-510 \mathrm{~nm})$ bands of Landsat TM/ETM+/OLI images, respectively.

EVI time series after the earthquake from May 2008 to July 2019 were composed in a chronological order. Clear observations (not contaminated by clouds or snow) for each pixel were used to interpolate contaminated observations by an ordinary least square (OLS) regression method (Zhu and Woodcock, 2014; Zhu et al., 2019). Landslide surface recovery were assed based on changing trends of post-seismic EVI.

\subsubsection{Clear observation selection}

To select high-quality observations, we first used the Fmask in the TOA product to mask all possible low-quality pixels, including clouds and its relating shadows and scan-line corrector (SLC)-off gaps (Zhu et al., 2015; Zhu and Woodcock, 2012). The quality of pixels was marked by the Fmask and it can be used to remove most clouds, cloud shadows and circus clouds except some thin clouds and haze, which can be mistakenly regarded as EVI drop by landslides. To remove these low-quality pixels left by the Fmask, we used a simple Landsat cloud score algorithm from the Google Earth Engine to further remove clouds (Gorelick et al., 2017). By incorporating visible, near infrared, shortwave infrared and thermal infrared bands, this algorithm computed cloud score from 0 (clear pixel) to 100 (most likely cloudy pixels) (https://code.earthengine.google.com/dc5611259d9ccab952526b3c2d05ce07).

We further used the Normalized Difference Snow Index (NDSI) to exclude the influence of snow in all images. 
$110 \quad \mathrm{NDSI}=\frac{\rho_{\text {swir }}-\rho_{\text {grn }}}{\rho_{\text {swir }}+\rho_{\text {grn }}}(2)$

where $\rho_{\text {swir }}$ and $\rho_{\text {grn }}$, are shortwave infrared $(1550-1750 \mathrm{~nm})$ and green $(520-600)$ bands of Landsat TM/ETM+/OLI images, respectively. From our tests we found NDSI > 0.4 can remove most snow.

\subsubsection{Ordinary least square (OSL) regression and landslide surface recovery prediction}

By nature, vegetation index would change gradually in a year-round (Chen et al., 2004; Yang and Qi, 2017) and the OLS

115 regression is a commonly used way to restore bad observations by clouds and snow in time series of Landsat images (Zhu and Woodcock, 2014; Zhu et al., 2019). In this work, we performed the OLS for both the pre- and post-seismic EVI time series. We calculated EVI on 15 July for all years, because at this time of the year, the solar incidence angle is near the highest, which could minimize the influence of mountain shadows in rugged terrains. In addition, EVI is near its annual peak values on 15 July, when it is less likely influenced by inter-annual fluctuations of vegetation phenology.

120 From previous works (Yang and Qi, 2017; Yang et al., 2018b), it is justifiable to assume annual vegetation index on most landslide surfaces change linearly in post-seismic years. For each pixel, the OSL regressed EVI values in all post-seismic years (2008-2019) on 15 July has been used to construct a linear regression line and the slope of the line for each location is used as landslide recovery rate.

\subsubsection{Analyses of influencing factors}

125 We used the landslide inventory interpreted by Xu et al. (2014) to select Landsat observations on co-seismic landslides. To explain the spatial patterns of landslide recovery, EVI increasing rates were plotted with twelve environmental factors, including: slope, pre-seismic vegetation condition, landslide depth, landslide area, elevation, ground peak acceleration of the earthquake, aspect, slope curvatures, topographic positions, mean annual precipitation, ground cohesion strength and vegetation types.

130 The landslide area is an attribute of the landslide inventory interpreted by Xu et al. (2014). Ground peak acceleration of the 2008 earthquake can be found from the USGS ShakeMap. Gallen et al. (2015) derived near-surface cohesion by incorporating fracturing. Their derived rock strength was used to study its influence on landslide surface recovery in this work. Mean annual precipitation was provided by the Institute of Mountain Hazards and Environment, CAS (http://english.imde.cas.cn/). Vegetation type data is from Zhang et al. (2007) and this data has also been used in other related works (Yang and Qi, 2017).

135 All other topographic factors were derived from a $25 \mathrm{~m}$ DEM digitized from a 1:50,000 topography map before the earthquake (also used by Fan et al., 2012). Percent slope, aspect directions, planform and profile curvatures were calculated from the DEM in ArcMap 10. Aspect was transformed into aspect index $I_{a s p}$ by the following formula:

$$
I_{\text {asp }}=\mid \operatorname{COS}((\text { aspect }-22.5) / 180 \times \pi / 2) \mid
$$

where, aspect is calculated from ArcMap 10. $I_{a s p}$ ranges from 0 to 1. Southern aspects have lower values near 0, whereas northern aspects have higher values near 1 . 
In our study area, we randomly generated one million points. There are 47,076 points fall within co-seismic landslides. We picked out all abovementioned factors from these points on co-seismic landslides and studied their relation with landslide surface recovery.

\section{Results}

\section{3.1 Spatial patterns of landslide recovery}

Fig. 2 shows landslide surface changing rates measured in annual EVI increasing rate over the entire study area. Annual landslide recovery rates are shown in four categories: $<7 \times 10^{-3}, 7-14 \times 10^{-3}, 14-21 \times 10^{-3}$, and $>21 \times 10^{-3}$. The spatial pattern of landslide recovery in the study area is heterogeneous. Most landslides near the epicentre area, Yingxiu, have the best recover rate (blue pixels) during the study period, whereas landslides (red pixels) on high mountains (Fig. 2a) are poorly recovered.

150 The poorest recovery of landslide surface is found located on top of the Longmen mountain. These landslides are probably still bare debris with little vegetation cover.

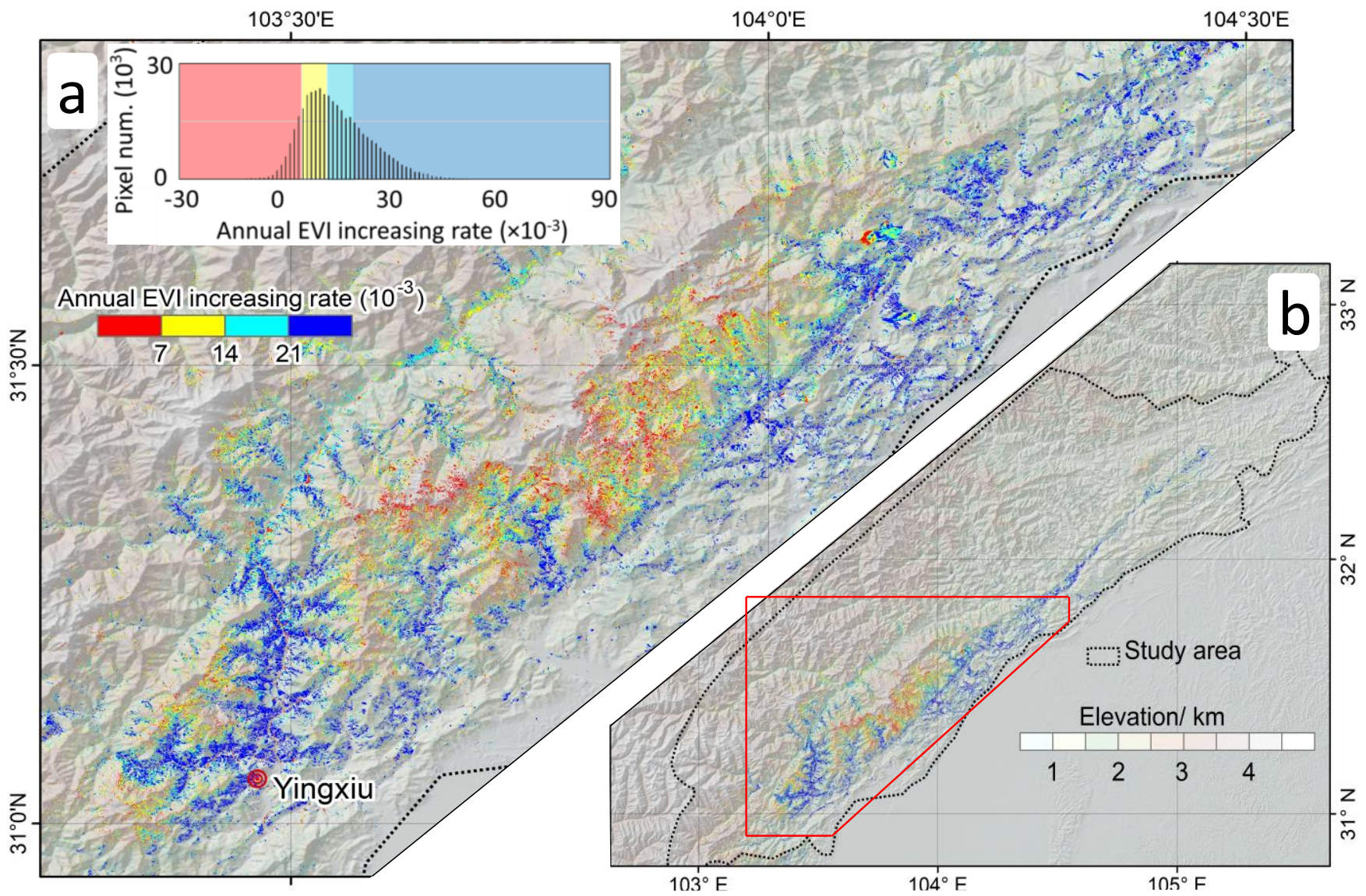

Figure 2: A heterogeneous spatial pattern of the co-seismic landslide surface recovery after the Wenchuan earthquake. The shown DEM is SRTM DEM downloaded from the USGS website. The hillshade data is produced by the authors by using ArcGIS. 
155 Inset in Fig. 2 is a histogram showing the frequency distribution of annual EVI increasing rate on co-seismic landslides. Landslide recovery rate ranges from -30 to $90 \times 10^{-3}$, but more than $99 \%$ landslide surfaces have positive rates. The mean recover rate on all co-seismic landslides in our study area is $17 \times 10^{-3} .11 .4 \%$ co-seismic landslides have an annual EVI increasing rate $<7 \times 10^{-3}$ and the rate on $31.4 \%$ co-seismic landslides ranges are within $7-14 \times 10^{-3}$. Annual EVI increasing rate on the other two categories, $14-21 \times 10^{-3}$ and $21 \times 10^{-3}$, cover $27.2 \%$ and $30.0 \%$ of co-seismic landslides in the study area (inset

160 in Fig. 2a), respectively.

\subsection{Relations between landslide recovery and environmental factors}

To decipher possible influencing factors on landslide surface recovery, we analysed the relations between annual EVI increasing rate and twelve environmental factors: elevation, slope, aspect, topographic position, planform curvature, profile curvature, mean annual precipitation, ground peak acceleration, landslide area, pre-seismic mean EVI, near surface effective cohesion and vegetation type (Fig. 3). Although annual EVI increasing rates have a wide range $\left(-30-90 \times 10^{-3}\right), 82.0 \%$ coseismic landslides have recovery rates between 0 to $25 \times 10^{-3}$. In Fig. 3, we can see that these twelve factors influence landslide recover rates are within the range of 0 to $25 \times 10^{-3}$.

To clearly compare the influence of different factors on annual EVI increasing rate, all figures in Fig. 3 have the same scale of vertical axis (i.e. the annual EVI increasing rate ranges from 0 to $25 \times 10^{-3}$ ). Among these twelve factors, elevation, TPI and

170 pre-seismic EVI are the top three factors that have a wide influencing range. Elevation and TPI have similar negative relations with landslide recover rates. Recover rate decreases when elevation or TPI have higher values. Above an elevation of $1400 \mathrm{~m}$, EVI increasing rate decrease $0.7 \times 10^{-3}$ per 100 elevation increase. EVI increasing rate increases with the multi-year mean preseismic EVI, when the pre-seismic value is lower than 0.75 .

In general, ground peak acceleration and landslide area have complex positive relations with the annual EVI increasing rate.

175 Aspect index and near surface effective cohesion have slight negative relations with the annual EVI rate. The other factors, such as the mean annual precipitation, slope, curvatures and vegetation type seems to have little influence on the annual EVI increasing rate. 
https://doi.org/10.5194/esurf-2020-106

Preprint. Discussion started: 29 December 2020

(c) Author(s) 2020. CC BY 4.0 License.
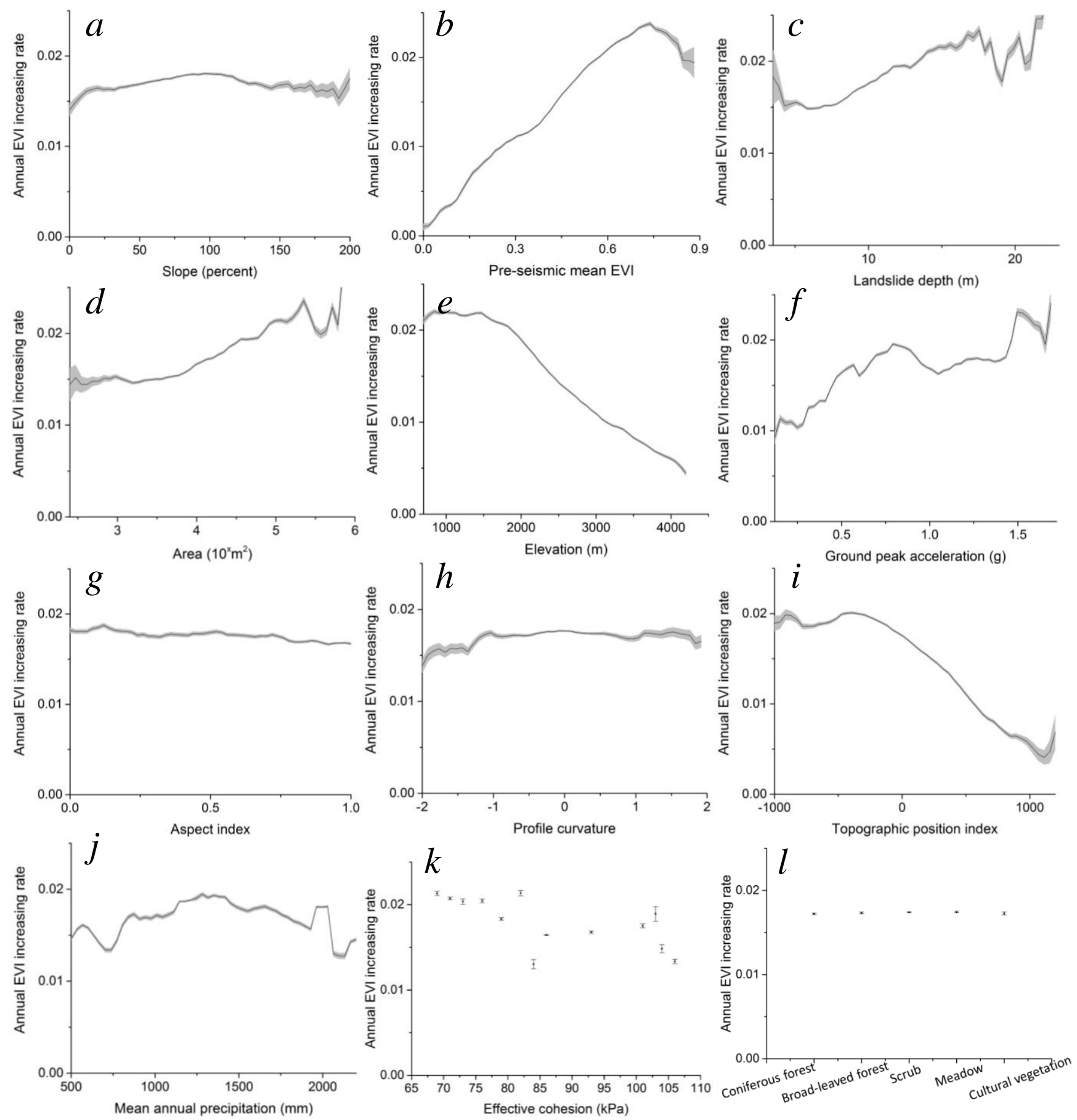

Figure. 3. Relations between environmental factors and landslide recovery rate (measured as annual EVI increasing rate). Lines in a-l are mean values and grey zones are standard error of the means. Point and bars in $k$ and $l$ are mean values and SEM, respectively. 


\section{Discussion}

\subsection{Heterogeneous recovery of landslide surface after the Wenchuan earthquake}

Monitoring post-seismic landslide changes needs large coverage and long-term observation efforts, because earthquaketriggered landslides are widely distributed (Xu et al., 2014) and are very dynamic in post-seismic years (Li et al., 2018; Yang, et al., 2017). By using high spatial resolution images, previous studies found significant and consistent recovery of co-seismic landslide surface and predicted that landslide surface can be fully recovered by vegetation in around a decade in partial region (near the epicentre area and the Mianyuanhe area) (Fan et al., 2018; Li et al., 2016; Tang et al., 2016; Yang et al., 2017). Extrapolations of observations from part of the earthquake-affected area to the whole region may not hold true. For the entire earthquake-affected region, we studied post-seismic vegetation recovery on landslides and found the recovery of co-seismic landslides is spatially heterogeneous. Co-seismic landslides in high Longmen mountain have very poor recovery performances. Results of this work support the findings made by Yang and Qi (2017), but it has much higher spatial resolution to reveal more detailed spatial patterns. Our results suggest distinct patterns of landslide evolution may exist in different parts of the earthquake-affected region in post-seismic years.

\subsection{Influencing factors on post-seismic landslide recovery}

195 To explain the spatially heterogeneous pattern of landslide recovery, we used twelve environmental variables. For the entire region, elevation, TPI and pre-seismic EVI have the most significant influences. The negative relation with TPI indicate that landslides recover faster on valleys (lower than its nearby locations) than on ridges (higher than its nearby locations). This finding indicates that landslide deposits may stay on hillslopes rather than flow down to valleys in post-seismic years (Fan et al., 2018). Although we cannot quantify the volume of landslide deposits that stayed on hillslopes, a large part of these materials cannot be transported, which may influence the competition between co-seismic uplift and erosion in this region (Parker et al., 2011).

Its relation with elevation indicates that higher elevation has lower temperatures and may lead to slower recovery rates. The pre-seismic EVI is an important indicator for plant physiology and its positive relation with the landslide recover indicates earthquake-triggered landslide did not significantly change vegetation growing conditions. These three dominant factors indicate that post-seismic landslide recovery is collaterally controlled by topography and plant physiology conditions. Although not all factors pose the same significant influences on landslide recovery, different ones may dominate the recovery process at the local scale.

The relation with mean annual precipitation is complex. It is known that climate drives erosion of landslide deposits (Tolorza et al., 2019; Zhang et al. 2019). Precipitation also plays a positive role in vegetation recovery, which is against erosion processes on landslide surfaces (Yang et al., 2018b). To quantify the role of climate on landslide erosion, detailed information on rainfall events, such as duration and intensity should be known. The effects of an intense rainfall within a few minutes is 
different to the same amount of precipitation that last many days. The relation between climate and post-seismic erosion may be re-assessed by considering vegetation dynamics.

\subsection{Implication of landslide surface recovery}

215 Destruction of vegetation by co-seismic landslides leave unstable slope surface exposed and vegetation recovery on landslides could improve shallow slope stability (Kim et al., 2017). The recovery of landslide surface can be used to indicate the duration of a major mountain earthquake (Yang et al., 2018a). Root systems of recovered vegetation could improve soil strength preventing further slope mobilization (Shiels and Walker, 2013) and its canopy can mitigate rain drop splash on landslides, mitigating surface erosion. In addition, recovered vegetation can change landslide surface hydrology in three ways: 1) canopy intercept rainfall and decrease surface flow, 2) root system improve preferential flow, both can postpone soil saturation and prevent further landsliding; 3) evapotranspiration drain soil water, further decreasing soil moisture (Cowpertwait and Metcalfe, 2009; Meusburger et al., 2010). Despite the root system of recovered vegetation may only influence shallow landslides, its hydrological influence may have a deeper impact on substrates and bedrock weathering beneath top soils, which may relate to deep-seated landslides.

225 This work only studied landslide surface by using EVI as an index, yet recovery of landslide interior structure still deserves further examination. Although recovered vegetation is fragile and very sensitive to post-seismic mass wasting processes, its recolonization marks the most significant feature changes in post-seismic mountains and the recolonization of vegetation on landslide indicates an at least transient stability of the surface. Vegetation recovery on co-seismic landslide surface could also plays a positive role in reducing surface erosion.

\section{$230 \quad$ 4.4 Advantages of Google Earth Engine}

Major earthquakes, such as the Wenchuan earthquake, could trigger numerous landslides spreading very large regions. Studying regional landslide changes after major earthquakes is important for understanding geo-hazards after major disturbances, yet it is technically difficult to implement. This is because mapping landslides over very large regions requires many optical images of high quality. These images should not be covered by clouds, and should be acquired in summer seasons, when landslides are easily recognized from surrounding ground features. Images that meet these criteria is rare, especially in monsoon climate regions. Therefore, most works used a sub-set of the earthquake-affected region to study landslide changes. This is especially true for the Wenchuan region (Fan et al., 2018; Yang et al., 2015; 2017).

This work used a cloud-based platform, GEE, to map landslides using all available Landsat images from 2001 to 2019 over a large region. GEE is a cloud-based platform, on which users can write simple scripts on their personal computers and perform heavy computations on numerous Google's infrastructures. Using this platform, we can easily find replacement pixels from nearby date images to replace cloud contaminated pixels. This work only used Landsat images, because this is a consistent data with a long archive. Besides the Landsat data, other datasets such as the Sentinel-2 data are also available (Yang et al., 2019). 
In addition, the GEE can provide timely data to anywhere on the planet, which is crucial for hazard studies. The GEE updates Zangbo debris flow, impacts of these catastrophic geomorphic processes can be quickly assessed (Yang et al., 2019). By combining machine learning with the cloud-based platform, it has the potential to utilize large volumes of remote sensing data efficiently and has the potential to provide a new way in fast hazard mappings.

\section{Conclusions}

250 The 2008 Wenchuan earthquake triggered more than 190,000 co-seismic landslides spreading many thousand square kilometres. Mapping landslide recovery on these co-seismic landslides could be difficult. Using a cloud-based computing platform, GEE, this work mapped surface recovery of all co-seismic landslides with Landsat images from 2001 to 2019. We found $>99 \%$ landslide surfaces have been recovering since 2008, but the spatial pattern is very heterogeneous. In general, coseismic landslides on higher elevation ridges recover slower than landslides on valleys with lower elevations. Landslides on the high Longmen mountain have the slowest recover rates, whereas the epicentre area along the Min river valley has the fastest rates. Elevation, TPI and pre-seismic vegetation condition are top three most important factors that influence postseismic landslide recovery. In addition, pre-seismic EVI also have a strong relation with landslide recovery. Locations with better vegetation growing conditions before the earthquake usually have faster landslide recover rates.

\section{Acknowledgements}

260 This work was jointly supported by the National Science Foundation of China (NO. 41807500) and the "Fundamental Research Funds for the Central Universities" (No. 2019ZY33). The authors would like to show their gratitude to Professor Jing LiuZeng from China Earthquake Administration for constructive discussions and Dr. Chao Ma to provide the mean annual precipitation data. The GEE code to derive recovery rate of coseismic landslides can be accessed at: https://code.earthengine.google.com/a489a5beb38e7d9f81d832306cf92e46.

\section{Data availability}

Ground peak acceleration of the earthquake is available from the USGS website. Ground cohesion strength is provided by Sean F Gallen (Sean.Gallen@ colostate.edu). Elevation, slope, slope curvatures, aspect and topographic positions are derived from a 1:50,000 topographic map, which is provided by Prof. Cees van Westen (c.j.vanwesten@utwente.nl). The landslide inventory of the 2008 Wenchuan earthquake is provided by Prof. Chong Xu (xc11111111@126.com). Mean annual precipitation data is provided by Dr. Chao Ma (sanguoxumei@163.com). 
https://doi.org/10.5194/esurf-2020-106

Preprint. Discussion started: 29 December 2020

(C) Author(s) 2020. CC BY 4.0 License.

\section{Author contribution}

W.Y., W.Q. and J.F. conceived the work. W.Y. and W.Q. performed the analysis in GEE, J.F. analysed the factor analysis part.

\section{Conflict of interest}

The authors have no conflict of interest.

\section{References}

Behling, R., Roessner, S., Golovko, D., and Kleinschmit, B.: Derivation of long-term spatiotemporal landslide activity-a multi-sensor time series approach, Remote Sens. Environ., 186, 88-104, http://doi.org/10.1016/j.rse.2016.07.017, 2016.

Bell, T.W., Allen, J.G., Cavanaugh, K.C. and Siegel, D.A.: Three decades of variability in California's giant kelp forests from the Landsat satellites. Remote Sens. Environ., 128, 110811, http://doi.org/10.1016/j.rse.2018.06.039, 2018.

Chander, G., Markham, B.L. and Helder, D.L.: Summary of current radiometric calibration coefficients for Landsat MSS, TM, ETM+, and EO-1 ALI sensors. Remote Sens. Environ., 113, 893-903, http://doi.org/10.1016/j.rse.2009.01.007, 2009.

Chen, J., Jönsson, P., Tamura, M., Gu Z., Matsushita, B. and Eklundh, L.: A simple method for reconstructing a high-quality ndvi time-series data set based on the Savitzky-Golay filter. Remote Sens. Environ., 91, 332-344, http://doi.org/10.1016/j.rse.2004.03.014, 2004.

Chen, M., Tang, C., Xiong, J., Shi, Q., Li, N., Gong, L., Wang, X., and Tie, Y.: The long-term evolution of landslide activity near the epicentral area of the 2008 Wenchuan earthquake in China. Geomorphology, 367(15), 107317, http://doi.org/10.1016/j.geomorph.2020.107317, 2020.

Chen, T., Prishchepov, A.V., Fensholt, R., and Sabel, C.E.: Detecting and monitoring long-term landslides in urbanized areas with nighttime light data and multi-seasonal Landsat imagery across Taiwan from 1998 to 2017. Remote Sens. Environ., 225, 317-327, http://doi.org/10.1016/j.rse.2019.03.013, 2019.

Coe, J.A., Bessette-Kirton, E.K., and Geertsema, M.: Increasing rock-avalanche size and mobility in glacier bay national park and preserve, Alaska detected from 1984 to 2016 Landsat imagery. Landslides, 15, 393-407, http://doi.org/10.1007/s10346-017-0879-7, 2018.

Cowpertwait, P. and Metcalfe, A.V. (Springer): Introductory time series with R, Germany, 2009.

Cui, P., Lin, Y., and Chen, C.: Destruction of vegetation due to geo-hazards and its environmental impacts in the Wenchuan earthquake areas. Ecol. Eng., 44, 61-69, http://doi.org/10.1016/j.ecoleng.2012.03.012, 2012.

Fan, X., Domènech, G., Scaringi, G., Huang, R., Xu., Q, Hales, T.C., Dai, L., Yang, Q., and Francis, O.: Spatio-temporal evolution of mass wasting after the $2008 \mathrm{mw} 7.9$ Wenchuan earthquake revealed by a detailed multi-temporal inventory. Landslides, 15, 2325-2341, http://doi.org/10.1007/s10346-018-1054-5, 2018.

Fan, X., van Westen, C., Xu, Q., Gorum, T., and Dai, F.: Analysis of landslide dams induced by the 2008 Wenchuan earthquake. J. Asian Earth Sci., 57(5), 25-37, http://doi.org/10.1016/j.jseaes.2012.06.002, 2012.

Gallen, S.F., Clark, M.K., and Godt, J.W.: Coseismic landslides reveal near-surface rock strength in a high-relief, tectonically active setting. Geology, 43(1), 11-14, http://doi.org/10.1130/G36080.1, 2015.

Gorelick, N., Hancher, M., Dixon, M., Ilyushchenko, S., Thau, D. and Moore, R.: Google earth engine: Planetary-scale geospatial analysis for everyone. Remote Sens. Environ., 202, 18-27, http://doi.org/10.1016/j.rse.2017.06.031, 2017.

Hu, W., Huang, R., McSaveney, M., Yao, L., Xu, Q., Feng, M. and Zhang, X.: Superheated steam, hot co2 and dynamic recrystallization from frictional heat jointly lubricated a giant landslide: Field and experimental evidence. Earth and Planetary Science Letters, 510, 85-93, http://doi.org/10.1016/j.epsl.2019.01.005, 2019.

Huang, R. and Fan, X.: The landslide story. Nat. Geosci., 6, 325-326, http://doi.org/10.1038/ngeo1806, 2013.

310 Keefer, D. (2002). Investigating landslides caused by earthquakes-a historical review. Surv. Geophys., 23, 473-510, http://doi.org/10.1023/A:1021274710840, 2002.

Keefer, D.K.: The importance of earthquake-induced landslides to long-term slope erosion and slope-failure hazards in 
seismically active regions. Geomorphology, 10, 265-284, http://doi.org/10.1016/0169-555X(94)90021-3, 1994.

Khan, S.F., Kamp, U. and Owen, L.A.: Documenting five years of landsliding after the 2005 Kashmir earthquake, using repeat photography. Geomorphology, 197, 45-55, http://doi.org/10.1016/j.geomorph.2013.04.033, 2013.

Kim, J.H., Fourcaud, T., Jourdan, C., Maeght, J.L., Mao, Z., Metayer, J., Meylan, L., Pierret, A., Rapidel, B., Roupsard, O., Rouw, A., Sanchez, M.V., Wang, Y., and Stokes A.: Vegetation as a driver of temporal variations in slope stability: The impact of hydrological processes. Geophys. Res. Lett., 44, 4897-4907, http://doi.org/10.1002/2017GL073174, 2017.

Li, C., Wang, M., and Liu, K.: A decadal evolution of landslides and debris flows after the Wenchuan earthquake. Geomorphology, 323, 1-12, http://doi.org/10.1016/j.geomorph.2018.09.010, 2018.

Li, L., Yao, X., Zhang, Y., Iqbal, J., Chen, J., and Zhou, N.: Surface recovery of landslides triggered by 2008 Ms8.0 Wenchuan earthquake (china): A case study in a typical mountainous watershed. Landslides, 13, 787-794, http://doi.org/10.1007/s10346-015-0594-1, 2016.

Lin, G.W., Chen, H., Chen, Y.H., and Horng, M.J.: Influence of typhoons and earthquakes on rainfall-induced landslides and suspended sediments discharge. Eng. Geol., 97, 32-41, http://doi.org/10.1016/j.enggeo.2007.12.001, 2008.

Liu, F., Li, J., and Yang, S.: Landslide erosion associated with the Wenchuan earthquake in the minjiang river watershed: Implication for landscape evolution of the Longmen Shan, eastern Tibetan plateau. Nat. Hazards, 76, 1911-1926, http://doi.org/10.1007/s11069-014-1575-8, 2015.

Marc, O., Hovius, N., and Meunier, P.: The mass balance of earthquakes and earthquake sequences. Geophys. Res. Lett., 43, 3708-3716, http://doi.org/10.1002/2016g1068333, 2016.

Marc, O., Hovius, N., Meunier, P., Uchida, T., and Hayashi, S.: Transient changes of landslide rates after earthquakes. Geology, 43, 883-886, http://doi.org/10.1130/G36961.1, 2015.

Meusburger, K., Konz, N., Schaub, M., and Alewell, C.: Soil erosion modelled with USLE and Pesera using Quickbird derived vegetation parameters in an alpine catchment. Int. J. Appl. Earth Obs., 12, 208-215, http://doi.org/10.1016/j.jag.2010.02.004, 2010.

Mondini, A., Guzzetti, F., Reichenbach, P., Rossi, M., Cardinali, M., and Ardizzone, F.: Semi-automatic recognition and mapping of rainfall induced shallow landslides using optical satellite images. Remote Sens. Environ., 115, 1743-1757, http://doi.org/10.1016/j.rse.2011.03.006, 2011.

Ouimet, W.B.: Landslides associated with the May 12, 2008 wenchuan earthquake: Implications for the erosion and tectonic evolution of the longmen shan. Tectonophysics, 491, 244-252, http://doi.org/10.1016/j.tecto.2009.09.012, 2010.

Parker, R.N., Densmore, A.L., Rosser, N.J., De Michele, M., Li, Y., Huang, R., Whadcoat, S., and Petley, D.N.: Mass wasting triggered by the 2008 Wenchuan earthquake is greater than orogenic growth. Nat. Geosci., 4, 449-452, http://doi.org/10.1038/ngeo1154, 2011.

Saba, S.B., van der Meijde, M., and van der Werff, H.: Spatiotemporal landslide detection for the 2005 Kashmir earthquake region. Geomorphology, 124, 17-25, http://doi.org/10.1016/j.geomorph.2010.07.026, 2011.

Shiels, A.B. and L.R. Walker. Landslides cause spatial and temporal gradients at multiple scales in the Luquillo Mountains of Puerto Rico. In: G. González, M. Willig, and R. Waide, editors. Ecological Gradient Analyses in a Tropical Landscape. Ecological Bulletins. Blackwell Science, Oxford, U.K. 211-222. 2013.

Sidle, R.C., Furuichi, T., and Kono, Y.: Unprecedented rates of landslide and surface erosion along a newly constructed road in yunnan, china. Nat. Hazards, 57, 313-326, http://doi.org/10.1007/s11069-010-9614-6, 2011.

Stumpf, A. and Kerle, N.: Object-oriented mapping of landslides using random forests. Remote Sens. Environ., 115, 25642577, http://doi.org/10.1016/j.rse.2011.05.013, 2011.

Tang, C., Van Westen, C.J., Tanyaş, H., and Jetten, V.G.: Analysing post-earthquake landslide activity using multi-temporal landslide inventories near the epicentral area of the 2008 Wenchuan earthquake. Nat. Hazard Earth Sys., 16, 2641-2655,

355 http://doi.org/10.5194/nhess-16-2641-2016, 2016. reveal low postseismic erosion after the Maule earthquake (Mw8.8) during a severe drought. J. Geophys.Res. Earth. Surf., 124(6), 1378-1397, http://doi.org/10.1029/2018JF004766, 2019.

Xu, C., Xu, X., Yao, X., and Dai, F.: Three (nearly) complete inventories of landslides triggered by the May 12, 2008 Wenchuan mw 7.9 earthquake of china and their spatial distribution statistical analysis. Landslides, 11, 441-461, http://doi.org/10.1007/s10346-013-0404-6, 2014.

Xu, X., Wen, X., Yu, G., Chen, G., Klinger, Y., Hubbard, J., and Shaw, J.: Coseismic reverse- and oblique-slip surface faulting 
generated by the $2008 \mathrm{Mw} 7.9$ Wenchuan earthquake, China. Geology, 37, 515-518, https://doi.org/10.1130/G25462A.1, 2009.

Yang, W. and Qi, W.: Spatial-temporal dynamic monitoring of vegetation recovery after the Wenchuan earthquake. IEEE JSTARS, 10, 868-876, http://doi.org/10.1109/jstars.2016.2616511, 2017.

Yang, W., Qi, W., Wang, M., Zhang, J., and Zhang, Y.: Spatial and temporal analyses of post-seismic landslide changes near the epicentre of the Wenchuan earthquake. Geomorphology, 276, 8-15, http://doi.org/10.1016/j.geomorph.2016.10.010, 2017.

Yang, W., Qi, W., and Zhou, J.: Decreased post-seismic landslides linked to vegetation recovery after the 2008 Wenchuan earthquake. Ecol. Indic., 89, 438-444, http://doi.org/10.1016/j.ecolind.2017.12.006, 2018a.

Yang, W., Qi, W., and Zhou, J.: Effects of precipitation and topography on vegetation recovery at landslide sites after the 2008 Wenchuan earthquake. Land Degrad. Dev., 29, 3355-3365, http://doi.org/doi:10.1002/ldr.3098, 2018 b.

Yang, W., Wang, M., Kerle, N., Van Westen, C., Liu, L., and Shi, P.: Analysis of changes in post-seismic landslide distribution and its effect on building reconstruction. Nat. Hazard Earth Sys., 15, 817-825, http://doi.org/10.5194/nhess-15-817-2015, 2015.

Yang, W., Wang, Y., Sun, S., Wang, Y., and Ma, C.: Using Sentinel-2 time series to detect slope movement before the Jinsha River landslide. Landslides, 16, 1313-1324, http://doi.org/10.1007/s10346-019-01178-8, 2019.

Yunus, A. P., Fan, X., Tang, X., Jie, D., Xu, Q., and Huang, R.: Decadal vegetation succession from MODIS reveals the spatiotemporal evolution of post-seismic landsliding after the 2008 Wenchuan earthquake. Remote Sens. Environ., 236, 111476, http://doi.org/10.1016/j.rse.2019.111476, 2020.

Zhang, F., Jin, Z., West, A.J., An, Z., Hilton, R.G., Wang, J., Le, G., Densmore, A.L., Yu, J., Qiang, X., Sun, Y., Li, L., Guo, L., Xu, Y., Xu, X., Liu, X., Pan, Y., and You, C.: Monsoonal control on a delayed response of sedimentation to the 2008 Wenchuan earthquake. Sci. Adv., 5(6), eaav7110, http://doi.org/10.1126/sciadv.aav7110, 2019.

Zhang, S., Zhang, L.M., and Glade, T.: Characteristics of earthquake- and rain-induced landslides near the epicenter of Wenchuan earthquake. Eng. Geol., 175, 58-73, http://doi.org/10.1016/j.enggeo.2014.03.012, 2014.

Zhang, X. (The Geological Publishing House): The Vegetation Map of the People's Republic of China (1:1 000 000). Beijing,

Zhang, X., Wang, M., Liu, K., Xie, J., and Xu, H.: Using NDVI time series to diagnose vegetation recovery after major earthquake based on dynamic time warping and lower bound distance. Ecol. Indic., 94, 52-61, http://doi.org/10.1016/j.ecolind.2018.06.026, 2018.

Zhu, X. and Helmer, E.: An automatic method for screening clouds and cloud shadows in optical satellite image time series in cloudy regions. Remote Sens. Environ., 241, 135-153, http://doi.org/10.1016/j.rse.2018.05.024, 2018.

Zhu Z., Fu Y., Woodcock C.E., Olofsson P., Vogelmann J.E., Holden C., Wang, M., and Yu Y.: Including land cover change in analysis of greenness trends using all available landsat 5, 7, and 8 images: A case study from Guangzhou, china (2000 2014). Remote Sens. Environ., 185, 243-257, http://doi.org/10.1016/j.rse.2016.03.036, 2016.

Zhu, Z., Wang, S., and Woodcock, C.E.: Improvement and expansion of the fmask algorithm: Cloud, cloud shadow, and snow detection for Landsats 4-7, 8, and sentinel 2 images. Remote Sens. Environ., 159, 269-277, http://doi.org/10.1016/j.rse.2014.12.014, 2015.

Zhu, Z. and Woodcock, C.E.: Object-based cloud and cloud shadow detection in Landsat imagery. Remote Sens. Environ., 118, 83-94, http://doi.org/10.1016/j.rse.2011.10.028, 2012.

Zhu, Z. and Woodcock, C.E.: Continuous change detection and classification of land cover using all available Landsat data. Remote Sens. Environ., 144, 152-171, http://doi.org/10.1016/j.rse.2014.01.011, 2014.

Zhu, Z., Zhang, J., Yang, Z., Aljaddani, A.H., Cohen, W.B., Qiu, S., and Zhou, C.: Continuous monitoring of land disturbance based on Landsat time series. Remote Sens. Environ., 238, 111116, http://doi.org/10.1016/j.rse.2019.03.009, 2019. 